\title{
Increased energy expenditure in poorly controlled Type 1 (insulin-dependent) diabetic patients
}

\author{
K.S. Nair, D. Halliday and J.S. Garrow \\ Division of Clinical Sciences, Clinical Research Centre, Northwick Park Hospital, Harrow, UK
}

\begin{abstract}
Summary. The basal energy expenditure of 10 Type 1 (insulindependent) C-peptide-negative diabetic patients (2042 \pm $62 \mathrm{kcal} / 24 \mathrm{~h}$ ) was found to be significantly higher than the $1774 \pm 52 \mathrm{kcal} / 24 \mathrm{~h}$ predicted from their age, sex and body surface area $(p<0.01)$. Intravenous insulin treatment significantly reduced energy expenditure to $1728 \pm 19 \mathrm{kcal} / 24 \mathrm{~h}(p<$ 0.01 ), which matched predicted values. The observed increase in metabolic rate in uncontrolled diabetic patients is associated with increased protein turnover, increased plasma gluca-
\end{abstract}

gon, but no significant increase in cortisol, growth hormone or triiodothyronine concentrations in plasma. It may be accounted for by the energy cost of protein synthesis, or gluconeogenesis, or possibly increased sympathetic activity. This increased energy expenditure will contribute to the weight loss seen in Type 1 diabetic patients.

Key words: Energy expenditure, metabolic rate, Type 1 diabetes, diabetic control, glucagon.
In the early part of this century, when calorimetry was a major tool of investigation of metabolism in man, many workers measured metabolic rate in diabetic patients. The earliest documented report was that of Pettenkofer and Voit [1] who found no increased energy expenditure in diabetic patients. Many other animal and human studies during that period support this finding [2,3]. Benedict and Joslin [4] later reported that the oxygen consumption in diabetic patients expressed in terms of body weight was $16 \%-21 \%$ higher than in normal subjects. In reviewing this work, Lusk [5] criticised it on many points, and by recalculation of the data concluded that the metabolic rate of Benedict and Joslin's diabetic patients was only 5\% above normal. Allen and $\mathrm{Du}$ Bois [6] also disagreed with Benedict and Joslin, specifically with the expression of metabolic rate in terms of body weight. When metabolic rate was expressed in terms of surface area the difference between diabetic and control subjects disappeared. They also criticised Benedict and Joslin for not considering age in interpreting their data. In that pre-insulin period diabetic patients were emaciated and so Benedict and Joslin selected control subjects with low weight for comparison. Many of them had a metabolic rate $10 \%$ or more below the normal average. It was pointed out that these underweight subjects were likely to be malnourished, which that in itself would lower their metabolic rate [6]. There have been no conclusive studies on this subject reported in man. In dogs, pancreatectomy and the resulting diabetes did not affect the metabolic rate [3].

Many of the problems encountered by the pioneer workers in this area do not apply today. Well-controlled diabetic patients with normal weight were chosen for this study. Their metabolic rate was studied before and after insulin therapy to test the hypothesis that poor diabetic control results in increased energy expenditure. Such a study was accomplished conveniently by indirect calorimetry [7].

\section{Subjects and methods}

\section{Subjects}

Ten Type 1 diabetic patients (eight males, two females) were admitted to the metabolic ward after obtaining their informed consent for this study. The protocol was conducted according to the guidelines of the Northwick Park Hospital Ethical Committee. The protocol is reviewed first by a scientific scrutiny panel, and then by a committee which considers the ethical aspect (i. e. the danger or inconvenience to the patient compared with the value of the information gained). After approval by both committees the procedure (including possible dangers) is explained to the patient in the presence of a senior member of nursing staff, who judges if the patient understands and consents. Clinical data concerning the patients are given in Table 1. Patient no. 8 had early background retinopathy before insulin treatment was started. There had been no change in this condition for several years. Patient no. 10 suffered from moderate peripheral vascular disease. No 
Table 1. Clinical details of the diabetic subjects studied $(n=10)$

\begin{tabular}{lllllll}
\hline $\begin{array}{l}\text { Age } \\
\text { (years) }\end{array}$ & $\begin{array}{l}\text { Sex } \\
\mathrm{M}: \mathrm{F}\end{array}$ & $\begin{array}{l}\text { Weight } \\
(\mathrm{kg})\end{array}$ & $\begin{array}{l}\text { Height } \\
(\mathrm{cm})\end{array}$ & $\begin{array}{l}\text { Weight/height }{ }^{2} \\
\left(\mathrm{~kg} / \mathrm{m}^{2}\right)\end{array}$ & $\begin{array}{l}\mathrm{HbA}_{1 \mathrm{c}}{ }^{\mathrm{a}} \\
(\%)\end{array}$ & $\begin{array}{l}\text { Duration of } \\
\text { diabetes } \\
(\text { years })\end{array}$ \\
\hline $27.0 \pm 9.0$ & $8: 2$ & $68.0 \pm 9.0$ & $173.6 \pm 8.6$ & $22.38 \pm 2.31$ & $\begin{array}{l}\text { Insulin } \\
\text { require- } \\
\text { ment } \\
(\mathrm{U} / 24 \mathrm{~h})\end{array}$ \\
\hline
\end{tabular}

Observations expressed as mean $\pm \mathrm{SD}$

${ }^{a}$ Normal $<8.6 \%$ of total haemoglobin

other subjects suffered from any vascular, renal or cardiac complications at the time of the study.

All subjects were on a weight-maintaining diabetic diet $(250 \mathrm{~g} \mathrm{car}-$ bohydrate $+30 \mathrm{kcal} / \mathrm{kg}$ ideal body weight) for several months before the study. Their insulin was changed to 6-hourly neutral soluble insulin for $72 \mathrm{~h}$ before the study and withdrawn the night before the study. All subjects were studied after an overnight fast.

\section{Methods}

The metabolic rate was measured continuously using indirect calorimetry [7] whose accuracy was tested before and after every study using an alcohol lamp. The study was conducted in a thermoneutral environment with the patient resting in bed. Two readings of metabolic rate were recorded every $15 \mathrm{~min}$, and continued until at least four consecutive readings indicated a plateau. After plateau conditions for metabolic rate were achieved, six of the 10 patients (group A) each received an intravenous bolus dose ( $8 \mathrm{U})$ of soluble insulin, immediately followed by a constant infusion of insulin $(4.8 \mathrm{U} / \mathrm{h})$ for $3 \mathrm{~h}$. The remaining four patients (group B) did not receive insulin, but continued with an infusion of saline $(0.154 \mathrm{mmol} / \mathrm{l})$ for an additional $3 \mathrm{~h}$ after plateau metabolic rate was achieved. The study was repeated on a subsequent day in group B patients when their diabetes was well controlled with insulin. In both groups, intravenous glucose was given whenever the blood glucose concentration fell to $4 \mathrm{mmol} / 1$ to prevent symptomatic hypoglycaemia.

Blood glucose was monitored every $15 \mathrm{~min}$ using a reflectance meter (Reflomat, BCL Products, Lewes, East Sussex, UK). Blood samples, taken before the insulin infusion was started and at 30-min intervals until the end of the study, were kept in ice and centrifuged within $1 \mathrm{~h}$. Plasma glucose and serum bicarbonate were measured on the same day by a Beckman Glucose 2 analyser (Beckman, Palo Alto, California, USA). Other plasma or serum samples were stored at $-20^{\circ} \mathrm{C}$ until assayed for C-peptide, insulin, glucagon, growth hormone, cortisol, triiodothyronine and $\beta$-hydroxybutyrate.

Plasma C-peptide was assayed using a double antibody technique [8], using Guildhay C-peptide antiserum (Guildhay Antisera, Department of Biochemistry, University of Surrey, Guildford, Surrey, UK) and plasma glucagon using specific pancreatic glucagon antiserum [9]. Serum growth hormone was assayed using a human growth hormone radioimmunoassay kit (Serono Diagnostics, Slough, Bucks, UK), plasma cortisol using Guildhay radioimmunoassay kit, and serum triiodothyronine by a standard radioimmunoassay technique using specific antiserum.

Basal energy expenditure was calculated from the resting oxygen consumption (i.e. 1 liter $\mathrm{O}_{2}$ consumed $=4.825 \mathrm{kcal}$ ). Even though $\mathrm{CO}_{2}$ production rate and respiratory quotient were measured, we did not use them for calculating energy expenditure. Insulin deficiency and the consequent metabolic changes could result in hypercapnoea which should be reversed by insulin treatment. Thus, under the conditions of this investigation $\mathrm{CO}_{2}$ production rate based on measurements of expired $\mathrm{CO}_{2}$ is likely to be erroneous. The observed change in respiratory quotient when insulin was given would cause an overestimation of metabolic rate by about $3 \%$. From the age, sex, height and weight, the basal energy expenditure for every patient was predicted from the Mayo Clinic Table [10].

\section{Statistical analysis}

The significance of the difference between predicted and observed basal energy expenditure energy and that between energy expenditure before and after insulin treatment, were tested using Student's paired t-test. The significance of trends in metabolic rate with changes in hormone concentration was tested by linear correlation analysis. The degree of correlation of metabolic rate with diabetic control (based on the levels of bicarbonate and blood glucose) and plasma hormone levels was investigated.

\section{Results}

The predicted basal energy expenditure for the ten diabetic patients was $1744 \pm 52 \mathrm{kcal} / 24 \mathrm{~h}$ (mean \pm SEM) (Table 2). The observed energy expenditure in the uncontrolled state for groups A and B combined was $2042 \pm 60 \mathrm{kcal} / 24 \mathrm{~h}$, which was significantly higher than predicted $(p<0.01)$. Group A, having attained a metabolic-rate plateau for at least $1 \mathrm{~h}$, were given a primed continuous intravenous infusion of insulin and glucose to maintain the plasma concentration above $4 \mathrm{mmol} / \mathrm{l}$. Infusion of the insulin significantly reduced the metabolic rate $(p<0.01$; Fig. 1$)$. In group B the saline infusion did not significantly alter the metabolic rate, blood glucose level or level of hormones measured.

The only patient whose energy expenditure in the poorly controlled state was not higher than predicted was patient no. 3 who was hypothyroid at the time of the study: serum thyroxine was $3 \mathrm{nmol} / 1$ (normal range $60-150 \mathrm{nmol} / 1$ ), triiodothyronine $0.7 \mathrm{nmol} / 1$ (normal range $0.9-3.11 \mathrm{nmol} / 1)$ and thyrotrophin was more than $20 \mu \mathrm{U} / 1$. His energy expenditure was reduced from 1958 to $1778 \mathrm{kcal} / 24 \mathrm{~h}$ after insulin treatment. This was lower than predicted for him $(1958 \mathrm{kcal} / 24 \mathrm{~h})$, as expected in a hypothyroid patient.

The severity of the diabetes can be assessed by how low serum bicarbonate concentration is, and the excess energy expenditure by the difference between the observed and predicted values. On this basis the more severe the diabetes the greater the excess energy expenditure $(p<0.001)$. There is also a significant correlation between the increase in energy expenditure (observed predicted) and $\beta$-hydroxybutyrate levels $(p<0.01)$.

The change in metabolic rate is compared with changes in plasma growth hormone, cortisol, triiodothyronine, glucagon and glucose (Fig. 1). There is a sig- 
Table 2. Basal energy expenditure before and after insulin treatment, predicted basal energy expenditure, plasma glucose and serum bicarbonate

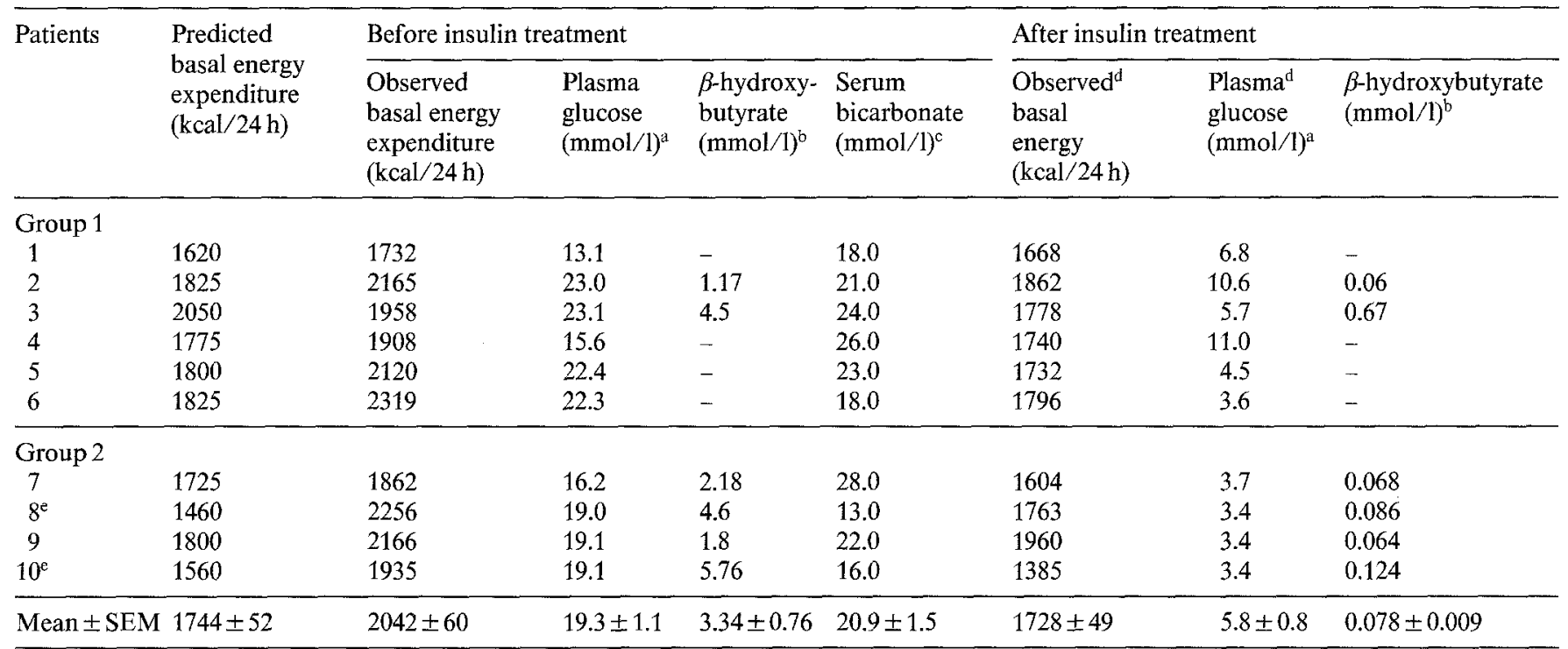

${ }^{a}$ Normal range $3.2-10 \mathrm{mmol} / 1$; ${ }^{\mathrm{b}}$ normal range $1.7 \pm 0.2$ (women) $0.9 \pm 0.2 \mathrm{mmol}$ (men); ${ }^{\mathrm{c}}$ normal range $20-30 \mathrm{mmol} / 1 ;{ }^{\mathrm{d}}$ measured during steady state; ${ }^{\mathrm{C}}$ female patients

nificant correlation between glucagon level and metabolic rate at each point measured $(n=54, r=0.58$, $p<0.01)$. The fall in glucose level reflects insulin action and this also is significantly correlated with metabolic rate $(n=20, r=0.76, p<0.01)$. Even though the mean cortisol level fell with insulin treatment, the change was not statistically significant. The plasma C-peptide level was below detectable limits in all the patients studied. There was a significant fall in $\beta$-hydroxybutyrate on insulin treatment.

\section{Discussion}

We have demonstrated increased energy expenditure in poorly-controlled diabetic patients, as compared with their own energy expenditure while on insulin treatment or predicted energy expenditure from standard tables. This increased energy expenditure could contribute to the weight loss in poorly controlled diabetes.

The increased energy expenditure was related to the degree of poor diabetic control judged by the bicarbonate concentration. However, even those diabetic patients who had a normal bicarbonate had a higher metabolic rate than predicted. This suggests that it was not acidosis which increased the energy expenditure but the lack of insulin.

Our measurement of different hormones demonstrated that only the plasma glucagon level had a significant correlation with energy expenditure. This does not prove that glucagon is responsible for the increased energy expenditure, but agrees with a report that glucagon increases oxygen consumption in rats [11]. Other hormones may also contribute to the energy expenditure. The action unopposed by insulin of all the catabolic hormones, especially catecholamine and cortisol, may
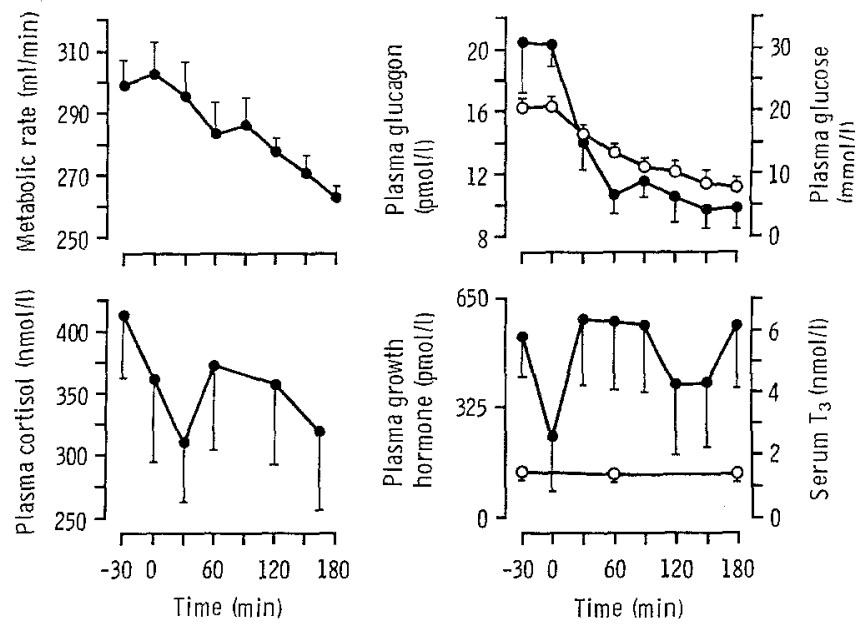

Fig. 1. Resting metabolic rate (oxygen consumption), plasma concentrations of glucagon $(-\mathbf{C})$, glucose $(\mathrm{O}-\mathrm{O})$, cortisol, growth hormone $\left(-\right.$ ) and serum triiodothyronine $\left(\mathrm{T}_{3}\right)(\mathrm{O}-\mathrm{O})$ in diabetic patients (group A) before ( $-30 \mathrm{~min}, 0 \mathrm{~min})$ and after insulin treatment $(30-180 \mathrm{~min})$

be important in this context. We have not assessed sympathetic activity in this study. Insulin withdrawal in diabetic patients for $41 \mathrm{~h}$ was not associated with any elevation of catecholamines [12], but an increased end-organ sensitivity to catecholamines cannot be excluded in diabetic patients. We have demonstrated that in poorlycontrolled diabetic patients there is increased protein breakdown and increased protein synthesis rate [13] and that these variables return to normal following insulin treatment [14]. Protein synthesis is undoubtedly an energy-consuming reaction [15], and it is therefore reasonable to assume that at least part of the increased energy expenditure we have demonstrated can be accounted for by the observed increase in protein turnover. 
Recently Ravussin et al. reported that during hyperinsulinaemic euglycaemic clamp in obese patients with Type 2 (non-insulin-dependent) diabetes/glucose intolerance, the glucose/insulin infusion needed to maintain euglycaemia was accompanied by a decrease in basal energy expenditure [16]. This was in contrast with other, glucose-tolerant, obese and lean control subjects who increased their basal energy expenditure. They proposed that the greater fall in gluconeogenesis in obese/ glucose-intolerant patients exceeded the effect of glucose storage on energy expenditure in these patients. A similar explanation is relevant in our Type 1 diabetic patients. Increased gluconeogenesis may also contribute to their increased energy expenditure.

If poor diabetic control increases basal metabolic rate this may mask glucose-induced thermogenesis. Such an observation has been interpreted as a thermic defect and a possible contributing factor to obesity [17]. In view of the demonstration of greater basal energy expenditure both in obese diabetic patients [18] and in the Type 1 diabetic patients in this study, it is misleading to interpret the reduced thermic response to a glucose meal in obese diabetic patients as a thermic defect. Obese subjects of all categories have greater energy expenditure than controls [19].

In conclusion, this study has demonstrated that poor diabetic control results in increased basal energy expenditure. This observation may be related to increased protein turnover secondary to the action of counterregulatory hormones unopposed by insulin. Increased gluconeogenesis and sympathetic activity may also contribute. This increased energy expenditure may account, at least in part, for the weight loss observed in poorly controlled diabetes.

Acknowledgements. Dr. R. F. Mahler's support has been invaluable for this study. We thank Professor S. R. Bloom and Dr. N.D. Christofides, Hammersmith Hospital, London, for assaying our samples for pancreatic glucagon. We are also grateful to S. Heels, J. Webster, and M. Lalloz for technical assistance. Dr. M. H. Haymond of Mayo Clinic, Rochester, Minnesota, USA, kindly measured the $\beta$-hydroxybutyrate in our samples.

\section{References}

1. Pettenkofer M, Voit C (1867) Über den Stoffwechselverbrauch in der Zuckerharnruhr. Zeitschr Biol 3: 380-444

2. Du Bois EF, Veeder BS (1910) Total energy expenditure in diabetes mellitus. Arch Intern Med 5: 37-46
3. Van Noorden C (1907) Energy exchange. In: Hall W (ed) Metabolism and practical medicine, Vol III. William Heinemann, London, pp 566-568

4. Benedict FG, Joslin EP (1910) Metabolism in diabetes mellitus. Carnegie Institution of Washington, Pub No 136: 188-234

5. Lusk G (1911) Metabolism in diabetes mellitus. Science NS 33; 433-434 [a review of Reference 4]

6. Allen FM, Du Bois EF (1916) Metabolism and treatment in diabetes. Arch Intern Med 16: 1010-1059

7. Garrow IS, Hawes S (1972) The role of amino acid oxidation in causing specific dynamic action in man. Br J Nutr 27: 211-219

8. Heding LG (1975) Radioimmunological determination of human C-peptide in serum. Diabetologia 11: 541-548

9. Christofides ND (1982) Pancreatic glucagon. In: Bloom SR, Ling RG (eds) Radioimmunoassay of gut regulatory peptides. WB Saunders, London, pp 74-79

10. Boothby WM, Sandiford I (1929) Normal values for standard metabolism. Am J Physiol 90: 290-291

11. Davidson IWF, Salter JM, Best CH (1960) The effect of glucagon on the metabolic rate of rats. Am J Clin Nutr 8: 540-545

12. Alberti KGMM, Christensen NJ, Iversen J, Orskov H (1975) Role of glucagon and other hormones in development of diabetic ketoacidosis. Lancet 2: 1307-1311

13. Nair KS, Garrow JS, Ford C, Mahler RF, Halliday D (1983) Effect of poor diabetic control and obesity on whole body protein metabolism in man. Diabetologia 25: 400-403

14. Nair KS, Ford C, Garrow JS, Halliday D (1983) Effect of insulin therapy on whole body protein turnover in diabetes. Diabetes 32 (Suppl 1): 33P

15. Payne PR, Waterlow IC (1971) Relative requirements for maintenance, growth and physical activity. Lancet $2: 210-211$

16. Ravussin E, Bogardus C, Schwartz RS, Robbins DC, Wolfe RR, Horton ES, Danforth E Jr., Sims EAH (1983) Thermic effect of infused glucose and insulin in man. J Clin Invest 72: 893-902

17. Golay A, Schutz Y, Meyer HU, Thieband D, Churchod B, Maeder E, Felber JP, Jequier E (1982) Glucose induced thermogenesis in non-diabetic and diabetic obese subjects. Diabetes 31: 1023-1028

18. Nair KS, Garrow JS (1984) Increased basal energy expenditure and reduced thermic response in diabetic patients. In: Hordon E, Forth D (eds) Proceedings of Fourth International Congress on Obesity - Satellite meeting on Regulation of Energy Expenditure John Libbey, London (in press)

19. Nair KS, Halliday D, Garrow JS (1983) Thermic response to isoenergetic protein, carbohydrate or fat meals in lean and obese sub. jects. Clin Sci 65: 307-312

Received: 12 October 1983

and in revised form: 13 March 1984

Dr. K.S. Nair

Division of Clinical Sciences

Clinical Research Centre

Watford Road,

Harrow

Middlesex, HAI 3UJ, UK 